\title{
A multi-analysis characterization of medieval and vernacular coating mortars in rural Valencia (Spain): An experimental study for a Heritage Action Plan
}

\author{
Juan A. García-Esparza ${ }^{a, *}$, Francisco Pardo ${ }^{\mathrm{b}}$, Luis M. Palmero ${ }^{\mathrm{c}}$ \\ a Department of Mechanical Engineering and Construction, Universitat Jaume I, Avda. Vicent Sos Baynat s/n, 12071 Castellón de la Plana, Spain \\ ${ }^{\mathrm{b}}$ Department of Education Sciences, Universidad CEU Cardenal Herrera, Calle Grecia, 31, 12006 Castellón de la Plana, Spain \\ ${ }^{\mathrm{c}}$ Department of Architectural Construction, Universitat Politècnica de València, Camí de Vera, s/n, 46022 València, Spain
}

\section{A R T I C L E I N F O}

\section{Article history:}

Received 5 July 2017

Accepted 23 October 2017

Available online 24 November 2017

\section{Keywords:}

External renderings

Lime mortars

Gypsum mortars

Vernacular landscape

\begin{abstract}
A B S T R A C T
Almost all the façades of rural vernacular constructions were rendered in order to protect and decorate the masonry walls. Therefore, this study has been carried out in order to identify and classify the different vernacular techniques for producing mortar over history in a given geographical region through the combination of petrophysic, chemical and organoleptic analysis, going on to classify and date constructions for which there were no recorded data. The results show that mortars do indeed contain a wealth of information, which situates these constructions in a specific period of history and allows relationships to be established between construction stages and techniques. The results have also demonstrated that mortars are mainly composed of lime rather than gypsum as was erroneously assumed before the study. So, the determination of components and techniques has been considered a crucial aspect to be taken into account when working on the conservation, of contemporary aesthetic interventions for which the combination of petrophysical, chemical and organoleptic analysis is necessary to guarantee compatibility between existing mortars and new ones.
\end{abstract}

(c) 2017 Elsevier Masson SAS. All rights reserved.

\section{Introduction}

The characterization of old mortar is of interest for archaeology and architecture [1-5], specifically in the field of monument restoration and conservation [6,7]. In the case under study - the analysis of mortars in vernacular architecture - our interest is focused on ascertaining whether or not the initial hypothesis held by some authors that time conditioning factors determine the quality of a given mortar is correct, or whether - as a second theory speculates - the quality of these mortars depends on the production process and/or the availability of natural materials and resources. In this regard, recent studies such as that by Moropoulou et al. [8] offer a precise analysis of the technology and incompatibilities of contemporary interventions on historic mortars, while Faria et al. [9] focuses on the suitability and durability of certain lime mortars over others.

\footnotetext{
* Corresponding author.

E-mail addresses: juan.garcia@uji.es (J.A. García-Esparza), francisco.pardo@uch.ceu.es (F.P. Fabregat), lpalmero@csa.upv.es (L.M.P. Iglesias).
}

A third major factor in this study is establishing the exact composition of historic mortars in the region studied in order to date and identify the relationship of the mortar production technique, and to provide rural vernacular constructions with recognition of a historic identity, rarely valued or known. Hence the need for further knowledge and the reversal of external coatings' removal process which alters the constitution and external appearance of vernacular buildings (Fig. 1).

Given the above, the aim of this study is the petrographic characterization of these materials, identifying composition, texture and porosity, as well as the relationships between them, as found in constructions in Historic Centres (HC) or in Peripheral Constructions (PC) (Fig. 2). Criteria are selected based on sample characteristics in order to establish typologies that are significant as construction mortars. The main aim of this study is to establish a relationship between the typologies obtained and the origin of the mortars: origin of the material, production process, placement in the building or construction period.

The characterization of mortars is important since the area $-28,799.30 \mathrm{Ha}-$ is in the process of being considered of special relevance because its vernacular values [10]. The place will 


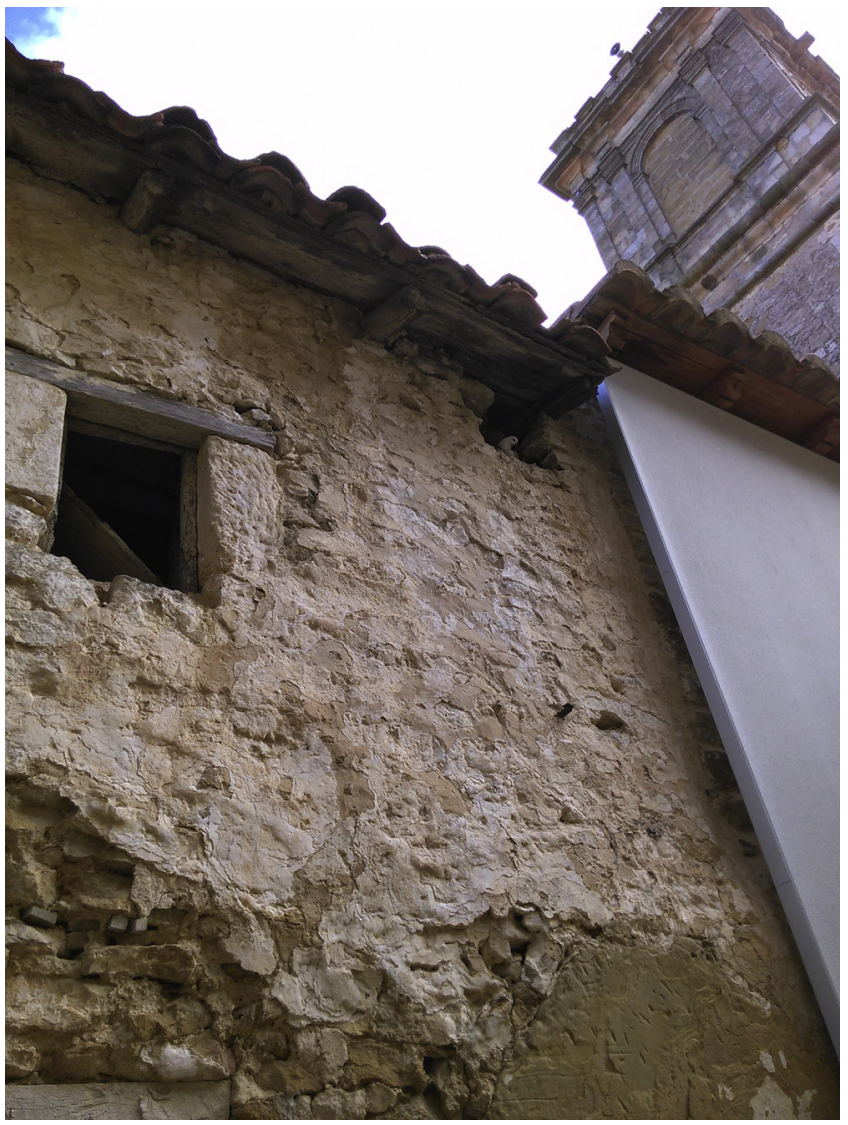

Fig. 1. Example of plundering process of historical coating mortars in Culla (Spain).

host a joint Territorial Heritage Action Plan between ten municipalities. As the map in Fig. 2 shows, from each village departs a pathway to the Peak of Penyagolosa Mountain. Villages and paths host more than 200 Constructions - houses, cottages, watermills, hermitages, etc. - that have been considered of interest. Thus, the rationale of the work relies on understanding the historical evolution of the place and its buildings by means of the mortars' morphology.

In doing so, the authors selected 36 samples of mortars from the different villages and pathways. Samples were codified - HCUSE-001 - meaning, HC or CP depending on the location of the building, USE meaning the acronym of the village were the sample was taken, and finally, the number that relates the sample with the building. In this regard, from the 36 samples, 14 were taken in HC and 22 in PC. As regards the location and the importance of the building, 8 samples were taken from US-les Useres village, 11 in CU-Culla, 4 in AT-Atzeneta, 3 in LC-Llucena, 2 in LDLudiente, 3 in VH-Villahermosa, 4 in PM-Puertomingalvo and 1 in TEU-Vistabella. Samples were taken from those parts of buildings where they are better preserved, eaves and jambs, notwithstanding that surface erosion was intrinsic to the most of the samples.

\section{Area of study}

The place of study is the Penyagolosa mountain range, in the province of Castellón, Spain. The scattered medieval settlements in the highlands, articulated throughout pathways (Fig. 1) took place due to necessity, and subsequently by self-sufficiency exploiting land resources. The vernacular dwelling, an epitome of a medieval culture based on mobility and a hand-to-mouth way of life, came to be seen as a symbol of stability [10]. Despite major economic and social changes, the autonomous households, the surviving spatial patterns, the buildings' arts and crafts, and the territorial histories contributing to the context persist to this day. So, it is believed that the most of the buildings that still remain in the landscape belong to the 16 th-18th century [11].

Pre-industrial mortars-making activity had defined specific duties: limekiln worker, mortar mixer, sand carriers, etc... [12]. As regards the characteristics of mortars, previous authors established the optimum combination of lime binders [13,14], while others established the conditions of hydraulicity of lime [15] and others the importance of the addition of small fragments of cooked clay and its dosage; mortars that are poor in lime in $1 / 3$ to $1 / 5$ [16,17].

Nonetheless, the normal production of common lime in preindustrial rural settings was done in a rural kiln when the stone was very close to the construction site or the wood was near the quarries. This was cheaper than resorting to kilns in urban centres. As a result, mortar often contained saltpetre, badly slaked lime, excessively coarse aggregate and vegetable remains including wood carbon or other fibres. Other mortars found near Penyagolosa are mortars with clay or earth mixes. But, it has not yet been established whether these mortars have a high index of hydraulicity by calcination as established by Vicat or are simply bastard mortars made up of clay earth [18].

The aggregate size comes in two categories, fine or coarse, depending on whether it resembles dust or a seed [19]. The aggregates are defined according to the type and quality of the closest stone material: siliceous or quartz, sandy, clay, grained stone, gypsum, or calcareous limestone. Cavanilles (1792-1793) described the mountains of the kingdom of Valencia as calcareous or sandy with small outcrops of gypsum [20]. It is therefore clear that the dosage of the different materials available and how they were produced greatly conditioned the mortar quality.

In 1785 , due to excessive cutting and thinning for charcoal productions, an order by the National Council requested that Economic Societies give preference to locations in which coal stone quarries could be found. This is why Cavanilles sees gypsum as a widespread resource in construction [20]. The gypsum used in rural settings was known as rough or black, also mixed with sand, lime and metal oxides. Mixed with sand this gypsum could double its volume and become extremely hard [19]. Bastard mortars were obtained that were one part gypsum with three parts lime-sand mix, with the increased volume neutralizing the reduction undergone by the lime and used to render external walls avoiding the cracks produced with the exclusive use of lime.

In general, the bonding agent used in the samples collected made use of clay, lime and gypsum, which bonded the mortar through different manufacturing, firing or alteration processes. Among these it is worth noting the binders that only suffer physical changes, such as those with clay, or those which experience chemical transformations such as binders containing calcium oxide $(\mathrm{CaO})$ which in the presence of carbon oxide $\left(\mathrm{CO}_{2}\right)$ transforms into calcium carbonate $\left(\mathrm{CaCO}_{3}\right)$ and crystallizes as calcite [21].

The samples of the study were taken from the foothills of the Iberian System. The climate in the area is marked by seasonal and daily thermal oscillations, which cause major stress in the interstices of the mortars, especially those exposed to solar radiation, which is intense in the summer with peaks of more than $30^{\circ} \mathrm{C}$ in July and August. Moreover, these tensions worsen in this region with the high number of days with freezing temperatures at night with peaks of $-5^{\circ} \mathrm{C}$ mainly in January; a mean of temperatures below zero practically 30 days a year (Table 1) [22]. These conditions are especially important in the case of these porous materials [23]. 
J.A. García-Esparza et al. / Journal of Cultural Heritage 31 (2018) 83-96

85

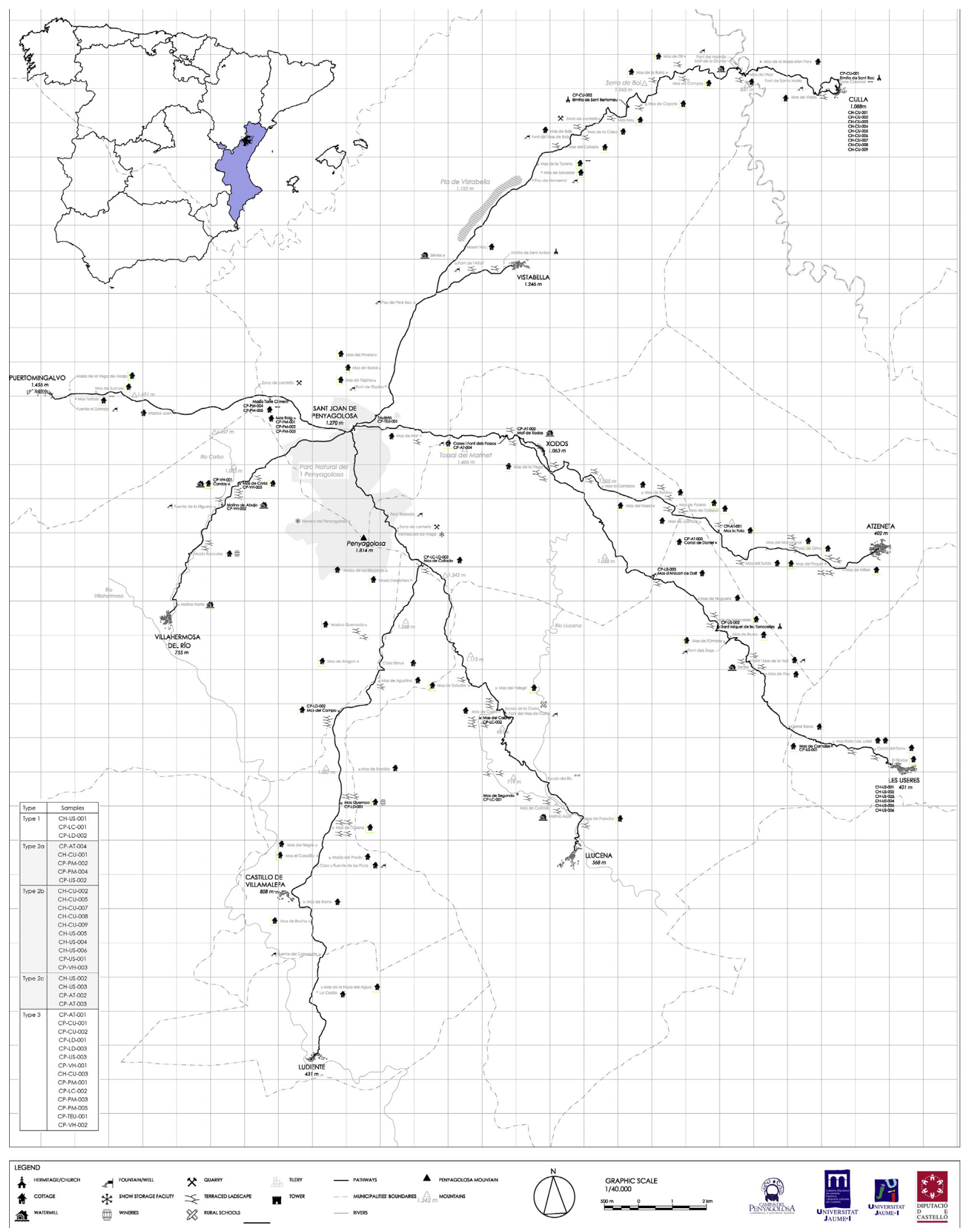

Fig. 2. Map with the dispersion of the samples. 
Table 1

Climate data for Vistabella del Maestrat, Penyagolosa Mountain.

\begin{tabular}{|c|c|c|c|c|c|c|c|c|c|c|c|c|}
\hline Climate data & Jan & Feb & Mar & Apr & May & Jun & Jul & Aug & Sep & Oct & Nov & Dec \\
\hline Mean temperature ${ }^{\circ} \mathrm{C}$ & 2.8 & 3.5 & 5.7 & 8.0 & 11.7 & 15.9 & 19.3 & 19.5 & 16.1 & 10.9 & 6.3 & 4.2 \\
\hline Mean maximum temperature ${ }^{\circ} \mathrm{C}$ & 6.6 & 7.6 & 10.4 & 12.8 & 16.6 & 20.8 & 24.4 & 24.5 & 20.9 & 15.3 & 10.7 & 8.7 \\
\hline Mean minimum temperature ${ }^{\circ} \mathrm{C}$ & -1.0 & -0.6 & 1.0 & 3.2 & 6.9 & 11.0 & 14.3 & 14.6 & 11.3 & 6.6 & 2.0 & -0.2 \\
\hline
\end{tabular}

National Agency of Climate

\section{Methodology}

\subsection{Characterization of the mortars}

In terms of composition, the mortars can either have petrographic components or a mineral composition. In the case of petrographic components a distinction was made between the aggregates from the bonding phase, determining their mineralogy and identifying ceramic, coal, and vegetable fragments. The chemical binder can be homogeneous in appearance or show a tendency to form lumps, pellets, and nodules or diffuse grains. This is connected with the purity of the lime and the degree of homogenization of the mix during the mortar production process.

The dosage or bonding agent ratio allows the texture type to be identified as granular, floating or massive. In this regard the petrographic characterization executed incorporates the observations upon sight and those made using the binocular loupe [24], a semiquantitative chemical analysis and a petrophysical analysis. The petrophysical one examined porosity and size and shape characteristics. Following the petrographic characterization, five mortar types were established, subsequently sorted into three typologies and two sub-typologies. The characteristics and frequency of each type allow their representation within the total analyzed sample to be assessed.

\subsubsection{Petrophysical analyses}

These tests help us understand the behaviour of stone materials when in contact with water, and their capacity to absorb it or cause it to evaporate. As in most cases, alteration processes depend on water circulation inside porous solids, these tests are important for ascertaining the age and durability of mortars depending on their exposure. These tests were performed on all mortar samples. Some samples did not provide results given the lack of coherence, especially in the case of samples rich in clay and low in chemical binder as they lost their consistency when introduced in water.

The petrophysical analyses were performed on irregular samples, always using portions as compact as possible in order to avoid the loss of high percentages of sample when submerging them. Due to their irregularity, the samples were prepared in paralleliped shapes following international guidelines [25-29]. The test tubes best suited to the test were chosen taking into account the specific limitations of these samples. The tests for determining the physical properties of the samples were performed in accordance with European norms UNE_EN 1097-3 for determining apparent density and porosity; UNE-EN 1097-6 for determining particle density and water absorption and UNE-EN 1097-7 for determining the real density of the filler using the pycnometer method (Table 2).

According to Table 2, the absorption coefficient, $\mathrm{C}_{\mathrm{abs}}$ (\%), is calculated by deducing the weight of the dry sample from the weight of the saturated sample. The result is divided by the weight of the dry sample and the value is multiplied by 100 . It is used to characterise the behaviour of mortars in contact with water. The freezing coefficient, $\mathrm{K}_{\mathrm{h}}(\%)$, is calculated by deducing open Porosity from total Porosity and the value is multiplied by 100 . If the result is equal or higher than $75 \%$ it can be said that the sample of mortar can be potentially frozen.
As can be observed in Table 2, the porosity of mortars tends to be high, although very variable, ranging between $10 \%$ and $40 \%$, with some samples even reaching $50 \%$ in this study. The pores are often intergranular, due to the low content of bonding agent or the relatively low quality of the mortar production. The porosymmetrical distribution of mortars is complex and there are usually several maximum radii of access to the pores. By analyzing data from Table 2 and a previous work from de la Torre [30] with similar samples, mortars with high lime dosages and clay minerals in its dosage, type 2 in this study, have a maximum of very small sizes, less than $0.1 \mu \mathrm{m}$. and their porous volume percentage is low, between 7 and $28 \%$. Other mortars with lower dosages, type 1 with gypsum as the main bonding element together with lime and type 3 with lime as bonding agent but without clay minerals in their composition, as suggested by de la Torre [30], have their maximum in larger sizes ( 1 to $0.1 \mu \mathrm{m}$ ).

\subsubsection{Chemical analysis}

3.1.2.1. X-ray fluorescence. The chemical composition of the total sample in a mortar can be poorly representative given the heterogeneous samples. As already stated, the aggregate is made up of different types of rock. In addition the bonding agent ratio is not constant in all samples, as the production for pre-industrial materials and processes could have varied greatly. Despite the number of mortar samples studied and the variety of constructions and periods to which these belong, the characteristics found in them could be considered relatively uniform.

Trace element content is also important when examining mortars, their groups and classification. However, this is greatly influenced by the heterogeneity of these materials and possible contamination processes which may have occurred between the time of execution and the present [30]. Twenty chemical elements were analyzed, although the tables only feature those above detection levels, so that differences between the various samples can be identified. Therefore, the values in Fig. 3 are a semi-quantitative approximation to mortar composition which, although somewhat homogenous, still displays the intrinsic heterogeneity of mortar, as can be observed in the organoleptic analysis.

The semi-quantitative assessment of the chemical analysis was executed using X-Ray Fluorescence (XRF) - S4 Pioneer spectrometer, Bruker from Universitat Jaume I. A margin of error of $+5 \%$ was assumed for the analysis [31]. The semi-quantitative analysis method was chosen as it provided a very approximate quantification of the concentration of the different elements in the samples using algorithms based on fundamental parameters of exciting, emitting and detecting X-rays.

3.1.2.2. X-ray diffraction. X-ray diffraction was used to obtain a structural characterization using the Bruker D4-Endeavor diffractometer to characterize the crystalline components. The crystalline phases of sample components were identified and quantified according to temperature, dehydration and phase transitions. Diagrams have made it possible to compare the results obtained from the samples of this study with others previously analyzed, and also to date and classify them accurately. The interpretation of the mineralogical analysis was performed by semi-quantitative analysis and following a percentage of approximation. The 
Table 2

Petrophysic properties of the samples.

\begin{tabular}{|c|c|c|c|c|c|c|c|}
\hline Designation & $\mathrm{V}_{\mathrm{R}}\left(\mathrm{cm}^{3}\right)$ & $\mathrm{Da}\left(\mathrm{g} / \mathrm{cm}^{3}\right)$ & $\mathrm{D}_{\mathrm{R}}\left(\mathrm{g} / \mathrm{cm}^{3}\right)$ & $\mathrm{C}(\%)$ & $\mathrm{P}(\%)$ & $\mathrm{C}_{\mathrm{abs}}(\%)$ & $\mathrm{K}_{\mathrm{h}}(\%)$ \\
\hline 2015CH-US-001 & 2.00 & - & 2.63 & - & - & - & - \\
\hline 2015CH-US-002 & 2.89 & 1.36 & 2.38 & 57.23 & 42.77 & 25.91 & 85.04 \\
\hline 2015CH-US-003 & 1.53 & 1.47 & 2.60 & 56.46 & 43.54 & 23.06 & 82.15 \\
\hline 2015CH-US-004 & 2.45 & 2.35 & 2.72 & 86.27 & 13.73 & 2.40 & 63.11 \\
\hline 2015CH-US-005 & 0.66 & 1.11 & 2.63 & 42.31 & 57.69 & 30.64 & 70.78 \\
\hline 2015CH-US-006 & 1.28 & 1.72 & 2.72 & 63.37 & 36.63 & 12.97 & 71.64 \\
\hline 2015CH-CU-001 & 2.79 & 1.37 & 2.58 & 53.24 & 46.76 & 24.34 & 77.78 \\
\hline 2015CH-CU-002 & 7.62 & 1.62 & 2.63 & 61.35 & 38.65 & 14.26 & 71.23 \\
\hline 2015CH-CU-003 & 2.84 & 2.06 & 2.59 & 79.55 & 20.45 & 13.72 & 161.14 \\
\hline 2015CH-CU-004 & 0.69 & 1,14 & 2.54 & 44.95 & 55.05 & 4.54 & 52.49 \\
\hline 2015CH-CU-005 & 11.04 & 1.76 & 2.51 & 70.36 & 29.64 & 9.11 & 68.59 \\
\hline 2015CH-CU-006 & 6.68 & 1,52 & 2.59 & 58.74 & 41.26 & 20.62 & 80.66 \\
\hline 2015CH-CU-007 & 7.74 & 2.52 & 2.68 & 93.82 & 6.18 & 0.48 & 55.46 \\
\hline 2015CH-CU-008 & 3.59 & 1.65 & 2.53 & 65.15 & 34.85 & 13.55 & 73.59 \\
\hline 2015CH-CU-009 & 11.30 & 1.80 & 2.53 & 71.25 & 28.75 & 5.01 & 59.30 \\
\hline 2015CР-АТ-001 & 3.45 & 1.45 & 2.65 & 54.85 & 45.15 & 21.20 & 75.96 \\
\hline 2015CP-AT-002 & 3.31 & 1.66 & 2.63 & 63.17 & 36.83 & 18.58 & 86.28 \\
\hline 2015CР-АТ-003 & 1.98 & 1.52 & 2.54 & 60.00 & 40.00 & 23.26 & 89.68 \\
\hline 2015CР-АТ-004 & 2.30 & 1.41 & 2.44 & 57.79 & 42.21 & 26.20 & 88.70 \\
\hline 2015CP-CU-001 & 4.46 & 1.49 & 2.52 & 59.31 & 40.69 & 23.95 & 89.23 \\
\hline 2015CP-CU-002 & 2.59 & 1.43 & 2.56 & 55.94 & 44.06 & 22.62 & 78.97 \\
\hline 2015CP-LC-001 & 3.50 & 1.35 & 3.07 & 44.03 & 55.97 & 28.03 & 75.56 \\
\hline 2015CP-LC-002 & 2.85 & 1.72 & 2.59 & 66.59 & 33.41 & 14.91 & 81.20 \\
\hline 2015CP-LD-001 & 3.35 & 1.61 & 2.61 & 61.58 & 38.42 & 15.89 & 74.97 \\
\hline 2015CP-LD-002 & 2.55 & 1.28 & 2.91 & 44.04 & 55.96 & 28.07 & 73.63 \\
\hline 2015CP-LD-003 & 2.10 & 1.19 & 2.60 & 45.85 & 54.15 & 37.50 & 84.83 \\
\hline 2015CP-TEU-001 & 5.89 & 1.51 & 2.61 & 57.75 & 42.25 & 24.84 & 89.86 \\
\hline 2015CP-US-001 & 2.32 & 1.68 & 2.52 & 66.48 & 33.52 & 17.78 & 89.94 \\
\hline 2015CP-US-002 & 2.69 & 1.40 & 2.55 & 54.79 & 45.21 & 28.61 & 89.36 \\
\hline 2015CP-US-003 & 0.41 & 1.42 & 2.56 & 55.41 & 44.59 & 22.86 & 78.50 \\
\hline 2015CP-VH-001 & 3.66 & 1.35 & 2.60 & 51.77 & 48.23 & 27.70 & 81.57 \\
\hline 2015CP-VH-002 & 5.28 & 1.63 & 2.58 & 63.31 & 36.69 & 16.30 & 78.53 \\
\hline 2015CP-VH-003 & 4.92 & 1.70 & 2.56 & 66.22 & 33.78 & 15.23 & 80.93 \\
\hline 2015CР-PM-001 & 2.69 & 1.46 & 2.59 & 56.28 & 43.72 & 24.71 & 84.97 \\
\hline 2015CР-PM-002 & 2.08 & 1.52 & 2.72 & 56.06 & 43.94 & 24.07 & 85.65 \\
\hline 2015CР-PM-003 & 6.95 & - & 2.77 & - & - & - & - \\
\hline 2015CР-PM-004 & 4.63 & - & 2.70 & - & - & - & - \\
\hline 2015CР-PM-005 & 4.57 & - & 2.69 & - & - & - & - \\
\hline
\end{tabular}

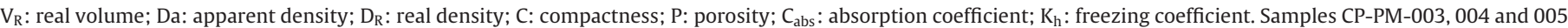
did not provide relevant results due to their lack of coherence.

diffractograms have been interpreted with the help of the computer application EVA of the firm Socabim and the JCPDS cards, until identifying the minerals present in each one of the samples.

\subsubsection{Petrographic-mineralogical analysis}

XRD was used to obtain the first approximation to a mortar composition identifying the bonding agent. However, it is necessary to use organoleptic methods, which allow the physical characteristics of lime and gypsum mortars to be understood upon sight and touch - hardness and tint. Visual analysis, supplemented with a Leica MZ APO microscope and subsequently XRF, allowed numerous intermediate cases to be recognised. These included lime mortars attacked by altered gypsum, bastard mortars of lime and gypsum or gypsum mortars with small amounts of calcite.

Visual examination was used to identify the variations in granulometry of the aggregate used in different samples. The types of aggregate observed were diverse, from nearby limestone and sandstone. During the extraction of samples considerable petrographic similarities could be observed between the masonry and the aggregate of the mortars. Some exceptions were found in certain samples, which were thought to be from relatively recent mortars given the appearance of the constructions.

Visual examination of the samples made it possible to identify components, such as remains of terracotta or fired clay, the presence of clay, remains of carbonised matter and even remains of organic structures - hyphae or fungal mycelium - whose presence may have been due to an alteration resulting from biodeterioration. There was a wide range of tones of the samples as they were affected by the type of chemical binder, aggregate, and the small impurities of clays or iron oxides (Fig. 4).

\section{Results and discussion}

The results obtained show it is possible to establish an initial classification depending on the binder. These can be distinguished into lime mortar and gypsum mortar depending on the chemical classification obtained using X-ray fluorescence. All samples analyzed are lime mortar except CP-LC-001, CP-LD-002, CH-US-001, which are gypsum mortars. It should be noted that among the lime mortars there are two samples, CP-PM-004 and CH-CU-003, with a higher siliceous percentage than calcium oxide (Table 3 ).

The mineralogical characterization of the samples revealed a prevalence of certain mineralogical phases. These can be classified into three types: hydrated calcium sulphate, quartz and calcite (Table 4). The presence of other mineral phases alongside the chemical characterization shows the presence of feldspar and clay minerals or associates. Following an initial organoleptic and petrophysical examination and taking into consideration the main mineral phases and chemical composition of the samples, three major sample typologies with their subtypologies were established.

The SEM/EDX analysis of the sample CP-LC-002 in Fig. 5 shows spectra with an intense signal of calcium (Ca), sulfur (S) and silicon ( $\mathrm{Si}$ ). If we look at the mappings of Fig. $5 \mathrm{c}$ and $\mathrm{d}$ it can be seen the distribution of these two elements (Ca) in the three layers and (S) just in the layer 1 . Therefore, it would be a gypsum mortar with siliceous arid. The result is confirmed in another area of the same 


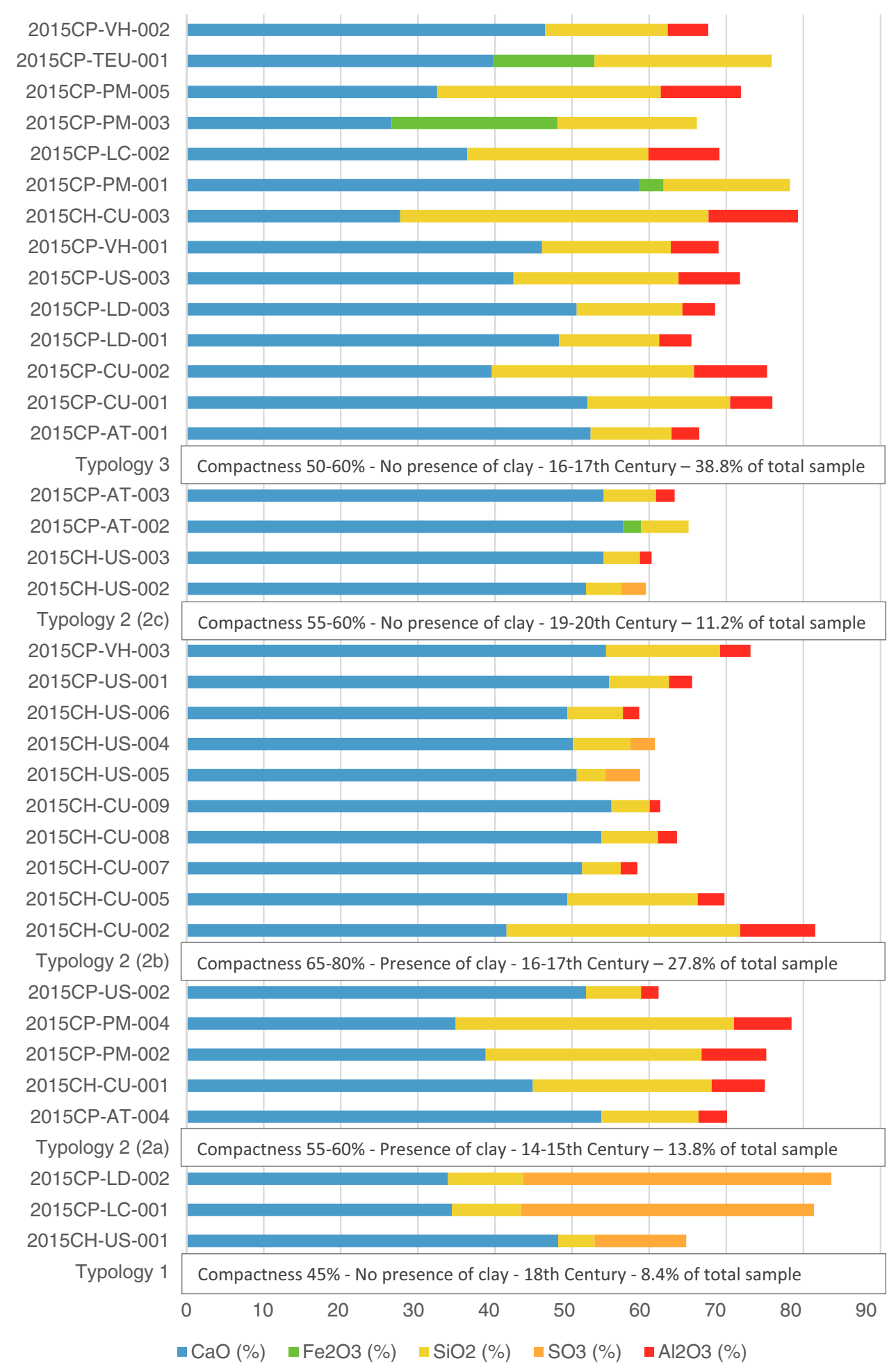

Fig. 3. Main characteristics of the typologies.

layer, being in this case the largest silicon peak for having selected an area with a higher concentration of aggregates.

\subsection{Type 1}

The first type corresponds to samples where the gypsum is the main bonding agent, as interpreted from the X-ray diffraction where the prevalent crystal phase is hydrated calcium sulphate compared to other phases such as orthoclase and quartz. $\mathrm{SO}_{3}$ in samples CP-LC-001 and CP-LD-002 is higher than 40\%, as confirmed by X-ray fluorescence. $\mathrm{SiO}_{2}$ and $\mathrm{AlO}_{3}$ maintain the coherence between both material characterization techniques, showing the presence of quartz sand. Finally, it should be noted that the presence of $\mathrm{CaO}$ and $\mathrm{MgO}$ forms part of the aggregates making up the mortars.

In organoleptic terms, within the first typology the role of gypsum is that of bonding agent alongside lime, CP-LC-001 and CP-LD-002, or as aggregate or alteration mineral CH-US-001. This 


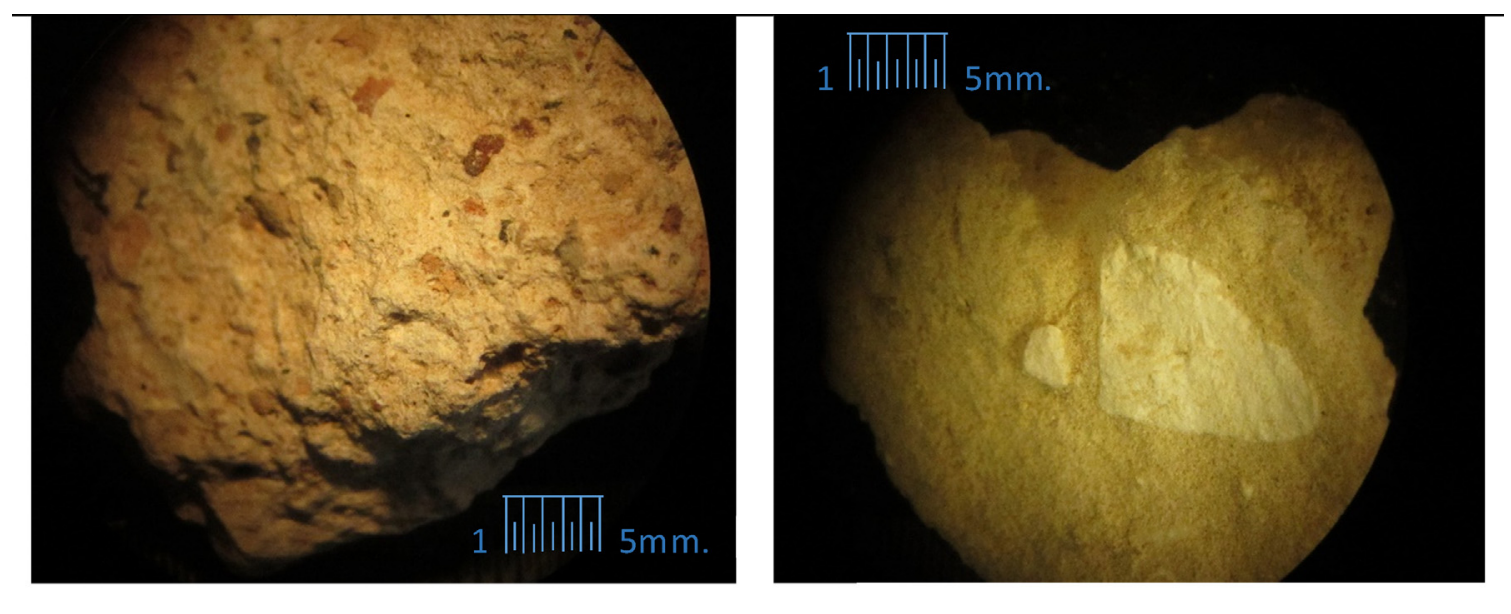

\section{Sample: 2015-CP-LD-002 / Typology 1}

Sample: 2015-CH-CU-001 / Typology 3
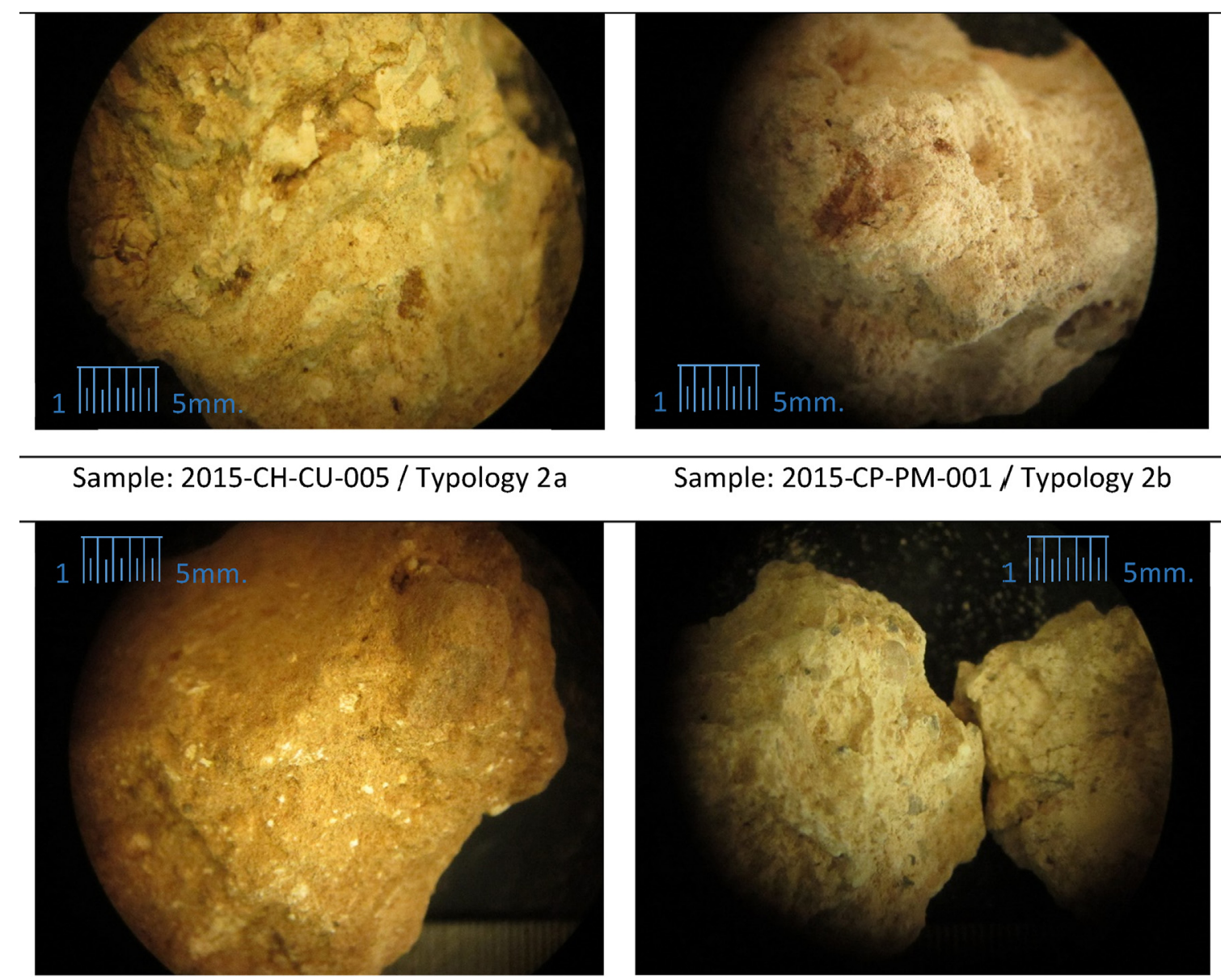

Sample: 2015-CP-PM-001/ Typology 2b

Sample: 2015-CP-TEU-001 / Typology 3 (4)

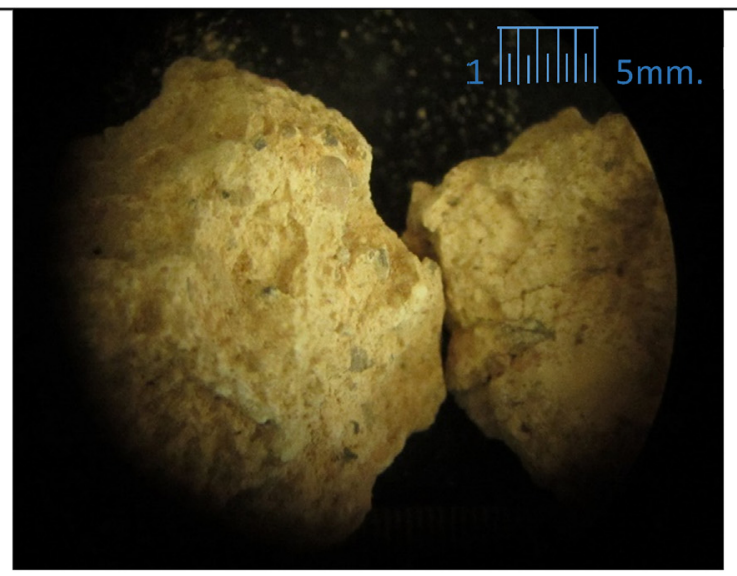

Sample: 2015-CP-AT-003 / Typology 5

Fig. 4. Organoleptic characterization of the samples.

sample is different to the previous ones, as the firsts are bastard mortars of gypsum and lime, while the latter has a bonding agent that is made up almost exclusively of lime, and the lime fills the pores. For this reason it is assumed that the last sample must have been originally a lime-based mortar, although it is now so deteriorated that it has mostly been replaced with alteration gypsum [32]. This is noted especially during optical microscopy and visual analysis (Fig. 4). As a bonding agent it appears in the form of a mass of fine acicular crystals. As an aggregate or impurity, in the form of non-calcinated fragments, it appears with textures characteristic of natural gypsum and when it is an alteration mineral it fills in pores and crack. Mortars with a gypsum-bonding agent are noticeably hard if they are in good condition, and under the microscope they show a great number of impurities: fragments of non-calcinated natural gypsum, and overcooked gypsum, as well as clay and marl nodules $[33,34]$. In general, type 1 samples present some small and 
Table 3

Identification of descriptive values of samples by X-Ray Fluorescence (XRF).

\begin{tabular}{|c|c|c|c|c|c|c|c|c|c|c|c|c|c|c|c|}
\hline Designation & $\mathrm{MgO}$ & $\mathrm{Al}_{2} \mathrm{O}_{3}$ & $\mathrm{SiO}_{2}$ & $\mathrm{P}_{2} \mathrm{O}_{5}$ & $\mathrm{SO}_{3}$ & $\mathrm{~K}_{2} \mathrm{O}$ & Cao & $\mathrm{MnO}$ & $\mathrm{Fe}_{2} \mathrm{O}_{3}$ & $\mathrm{Na}_{2} \mathrm{O}$ & $\mathrm{Cl}$ & PPC & $\mathrm{U}$ & Sum & Observation \\
\hline CP-LC-001 Typology 1 & 3.71 & 3.61 & 8.98 & - & 38 & 1.34 & 34.4 & 0.015 & 1.48 & - & - & 7.52 & $\%$ & 99.7 & $\begin{array}{l}\text { High rates of } \\
\text { gypsum and } \\
\text { magnesium }\end{array}$ \\
\hline CP-LD-002 Typology 1 & 1.49 & 3.54 & 9.73 & - & 40 & 1.64 & 33.9 & 0.028 & 1.53 & - & - & 6.98 & $\%$ & 99.5 & $\begin{array}{l}\text { High rates of } \\
\text { gypsum }\end{array}$ \\
\hline CH-CU-001 Typology 2a & 0.425 & 6.91 & 23.2 & - & 0.364 & 4.54 & 44.9 & - & 3.02 & 0.503 & 1.34 & 14.3 & $\%$ & 100 & $\begin{array}{l}\text { High presence of } \\
\text { potassium oxide }\end{array}$ \\
\hline CH-US-006 Typology 2b & 0.334 & 2.12 & 7.19 & 0.088 & 1.59 & 0.914 & 49.4 & 0.029 & 2.02 & 0.096 & 0.11 & 34.26 & $\%$ & 98.4 & $\begin{array}{l}\text { The only one with } \\
\text { phosphates }\end{array}$ \\
\hline CP-AT-002 Typology 2c & 0.403 & 1.83 & 6.18 & - & 0.22 & 0.985 & 56.6 & 0.022 & 2.33 & 0.038 & - & 31.30 & $\%$ & 100.2 & $\begin{array}{l}\text { High rates of } \\
\text { calcium }\end{array}$ \\
\hline CH-CU-003 Typology 3 & 0.379 & 11.6 & 40 & - & 0.206 & 4.64 & 27.7 & - & 4.57 & - & - & 8.52 & $\%$ & 99.0 & High rate of silica \\
\hline CP-TEU-001 Typology 3 & 0.586 & 7.11 & 23 & - & 0.0728 & 2.49 & 39.8 & 0.28 & 13.1 & - & - & 14.8 & $\%$ & 102.3 & $\begin{array}{l}\text { High rates of } \\
\text { Alumina and iron }\end{array}$ \\
\hline CP-PM-001 Typology 3 & 0.491 & 2.94 & 16.4 & - & 0.411 & 2.32 & 58.8 & - & 3.06 & 0.077 & - & 15.5 & $\%$ & 100 & $\begin{array}{l}\text { High rates of } \\
\text { calcium }\end{array}$ \\
\hline
\end{tabular}

Table 4

Mineralogical composition of samples by X-Ray Diffraction (XRD).

\begin{tabular}{|c|c|c|c|c|c|}
\hline & $\begin{array}{l}\text { CP-LD-002 } \\
\text { Typology } 1\end{array}$ & $\begin{array}{l}\text { CH-CU-001 } \\
\text { Typology 2a }\end{array}$ & $\begin{array}{l}\text { CH-CU-005 } \\
\text { Typology 2b }\end{array}$ & $\begin{array}{l}\text { CP-TEU-001 } \\
\text { Typology } 3\end{array}$ & $\begin{array}{l}\text { CP-PM-001 } \\
\text { Typology } 3\end{array}$ \\
\hline Quartz & + & ++++ & +++ & ++++ & ++++ \\
\hline Calcite & - & ++ & ++++ & +++ & + \\
\hline Illite/muscovite & - & $(+)$ & - & $(+)$ & (.) \\
\hline Orthoclase & + & $(+)$ & + & + & + \\
\hline Albite & - & - & - & - & $(+)$ \\
\hline Gypsum & +++++ & - & - & - & - \\
\hline Kaolinite & - & + & $(+)$ & - & - \\
\hline
\end{tabular}

+++++: > 75\%; ++++: > 50\%; +++: > 25\%; ++: >15\%; +: > 10\%; (+): presence (5-2\%); (.): (<2\%); -: no presence.

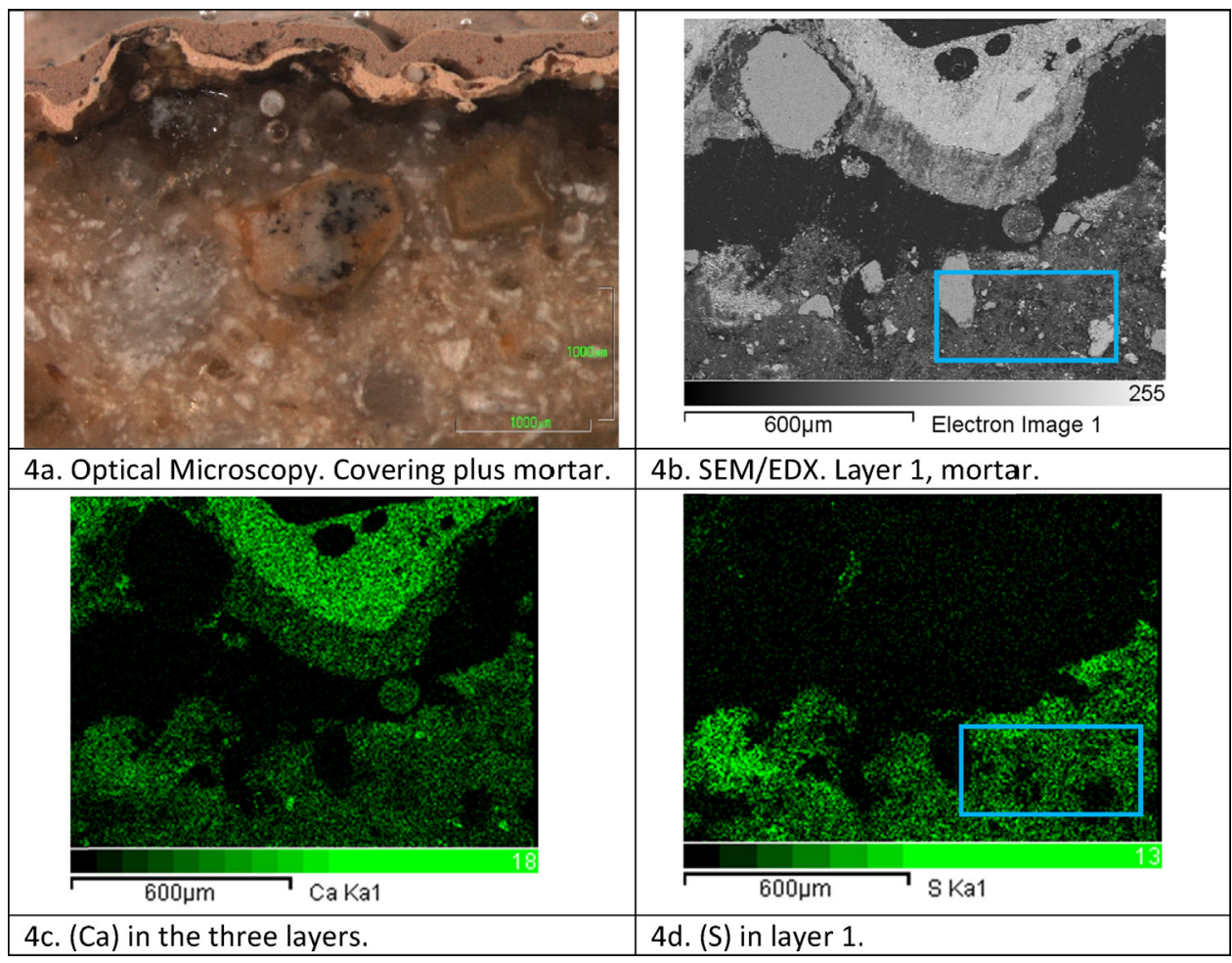

Fig. 5. CP-LC-002. Type 1. Optical Microscopy and Scanning Electron Microscopy (SEM/EDX).

medium non-calcinated lime nodules, remains of calcinated coals and occasionally fired clay. In terms of appearance, these samples are predominantly whitish (see Fig. 6).

The lime used in most of the mortars was non-hydraulic. In addition, it was also rather greasy, that is to say, it had a low content in
Mg. This was confirmed via a semi-quantitative XRF analysis. Carbonated lime tends to take the form of calcite, although in some instances of mixes with high lime content, a part of it precipitates in the form of aragonite [35]. Minerals which may suggest some degree of hydraulic nature (tobermorite or ettringite) were found 


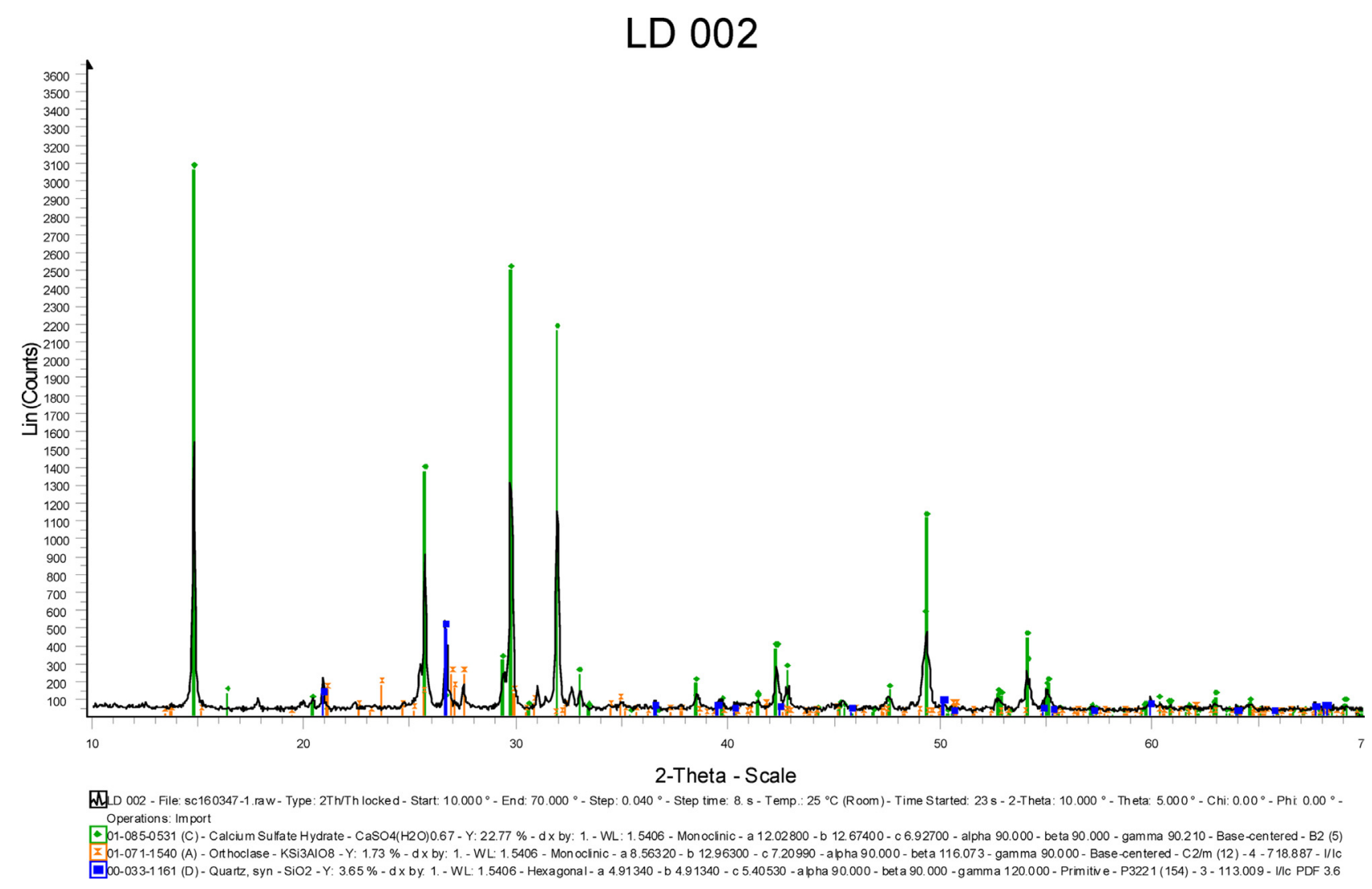

Fig. 6. XRD pattern of sample CP-LD-002.

only in samples CP-LC-002, CP-US-001, CH-CU-007, CP-TEU-001 due to the hardness, the greyish appearance of the chemical binder and the addition of vitreous reactive aggregate or ground brick. These samples were initially classified as type 4 given the occasional medium-sized lime nodules they presented, and the absence of vegetable remains except in $\mathrm{CH}-\mathrm{CU}-007$, with medium-sized aggregate and clay nodules. Mineralogical criteria were finally used to classify the first three samples as type 2 (2b) and CP-TEU-001 as type 3 (see Fig. 4 ).

Within type 1 we find samples with occasional variations in colour, especially due to the tone of the aggregate. In type 2 and 3 , in sample $\mathrm{CP}-\mathrm{VH}-003$ the lime nodules are large, while in samples CP-PM-003 and CP-PM-005 the lime nodules are small and their hardness and consistency are lower than the rest. Finally, sample $\mathrm{CP}-\mathrm{VH}-002$ very occasionally presents vegetable remains, $\mathrm{CH}-\mathrm{US}-$ 004 shows remains of fired clay and in $\mathrm{CP}-\mathrm{VH}-003$ the aggregate is finer than in the rest. Despite the differences in the organoleptic characteristics of the samples, due to the different manufacturing processes and availability of materials, chemical composition and petrophysical tests, compactness and porosymmetry of the total sample, a certain similarity could be suggested between the samples of type 2 (2a) and some of type 3 .

\subsection{Type 2}

The second typology is that of samples, which have lime as a bonding agent, but the main mineralogical phase is calcite followed by quartz with a presence of feldspar and kaolinite. These characteristically include large amounts of silica and lime oxide, as well as potassium oxide and aluminium oxide. This second large group is characterised by including clay minerals in its composition, as described in the following samples.
CH-CU-001 serves as a sample example for the second large group; lime mortar with a main mineralogical phase of quartz with a presence of clay; it is characterized by its lime bonding agent but the main mineralogical phase is quartz followed by calcite with a presence of orthoclase, illite and kaolinite. These characteristically include large amounts of silica and lime oxide as well as potassium oxide and aluminium oxide. The mineralogical characterization shows the presence of clay minerals as well as associated ones, as is confirmed by XRF (see Fig. 7).

$\mathrm{CH}-\mathrm{CU}-005$ is an example of samples from the third large group; lime mortar with a main mineralogical phase of calcite. The sample studied shows that the lime mortar is due to the widespread presence of calcite (56\%) with a high percentage of quartz (35\%) showing a large presence of quartz sand in the sample. The XRF for the sample confirms and is in agreement with these analyses as it shows large amounts of $\mathrm{CaO}$ and $\mathrm{SiO}_{2}$. It should be noted that there is a high presence of $\mathrm{KO}_{2}$ (4.54\%) in the sample, which explain the presence of orthoclase in the XRD. Therefore the presence of clay or other associated minerals such as the kaolinite provided by $\mathrm{AlO}_{3}$ and $\mathrm{SiO}_{2}$ is also observed (see Fig. 8).

In organoleptic terms the samples of type 2 (2a) and 3 are similar in appearance as they are made up of a chemical binder that is exclusively lime. It can be stated that the petrographic characteristics of lime mortars can be monotonous. The type of aggregate is almost always the same, subangular or subrounded fragments of limestone and sandstone. However, following a visual inspection several characteristic features identified the different samples, providing further information on their date and form of production. The samples classified as type 2 (2a) and whose mineralogical composition appears in Fig. 3 could be considered better quality lime mortars, as by touch the sample is surprisingly hard and coherent, due to the fine aggregate of the granulometric composition, which in some samples has been mixed with fired clay and in others with 


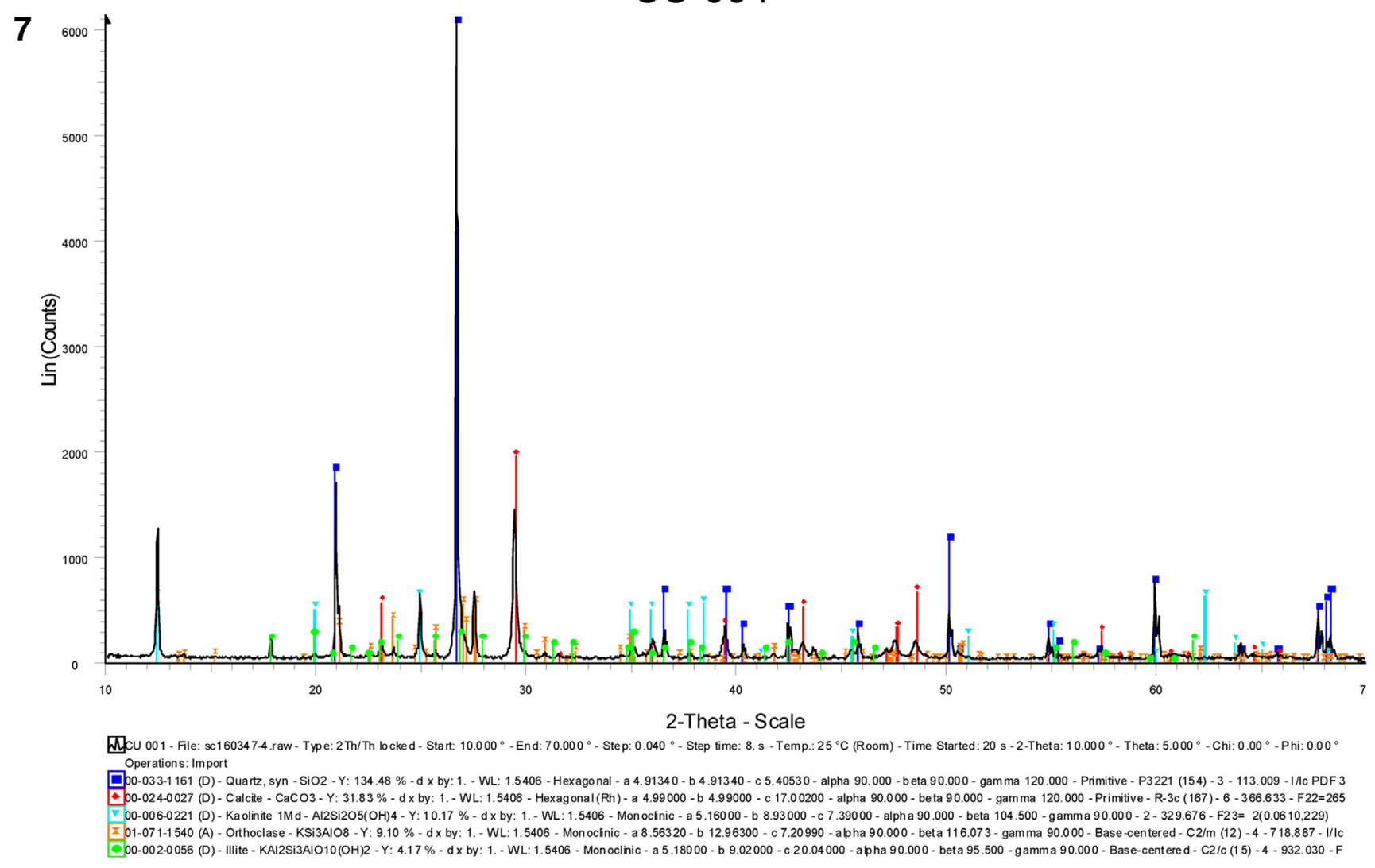

8

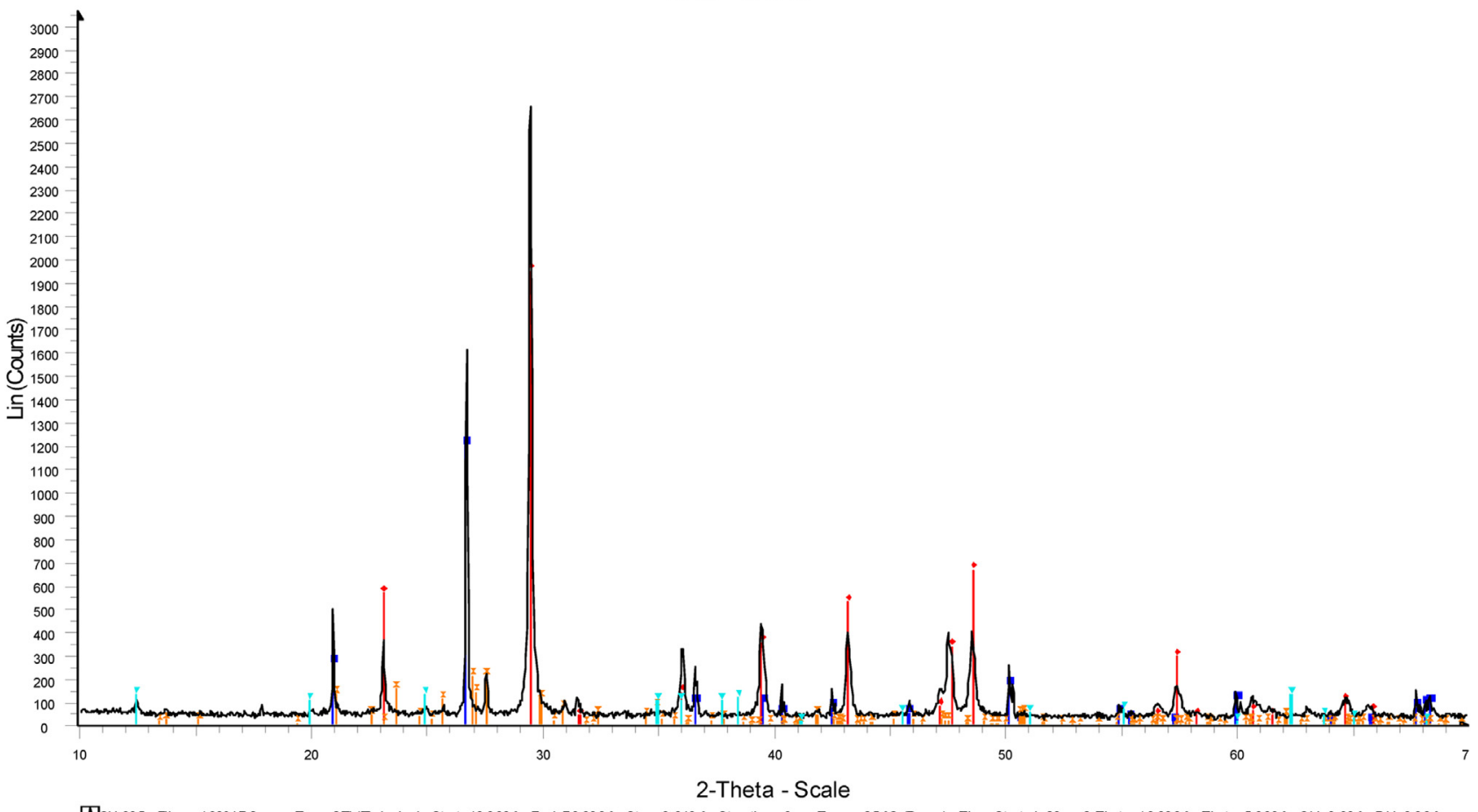

四cu 005 - File: sc1 $60347-2$ raw - Type: 2 Th/Th locked - Start: $10.000^{\circ}$ - End: $70.000^{\circ}$ - Step: $0.040^{\circ}$ - Step time: $8 . \mathrm{s}$ - Temp.: $25^{\circ} \mathrm{C}$ (Room) - Time Started: 20 s - 2 -Theta: $10.000^{\circ}$ - Theta: $5.000^{\circ}$ - Chi: $0.00^{\circ}$ - P hi: $0.00^{\circ}$ Operations: Import

口00-033-1 161 (D) - Quartz, syn - SiO2 - Y: $19.68 \%$ - d x by: 1. -WL: 1.5406 - Hexagonal - a 4.91340 - b 4.91340 - 5.40530 - alpha 90.000 - beta 90.000 - gamma 120.000 - Primitive - P3221 (154) - 3 - 113.009 - l/IC PDF 3. - b0-024-0027 (D) - Calcite - CaCO3 - Y: $31.83 \%$ - d x by: 1. - WL: 1.5406 - Hexag onal (Rh) - a 4.99000 - b 4.99000 - c 17.00200 - alpha 90.000 - be ta 90.000 - gamma 120.000 - Primitive - R-3c (167) - 6 - 366.633 - F22=265

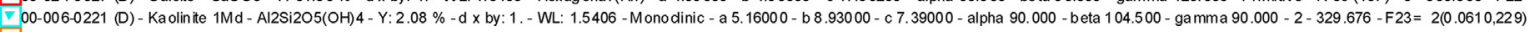
Z 01-071-1540 (A) - Orthoclase - KSi3AIO - Y: $3.39 \%$ - d x by: 1. - WL: 1.5406 - Monocinic - a 8.56320 - b 12.96300 - c 7.20990 - a pha 90.000 - beta 116.073 - gamma 90.000 - Base-centered - C2/m (12) - 4 -7 718.887 - I//C

Figs. 7-8. XRD pattern of samples $\mathrm{CH}-\mathrm{CU}-001$ and $\mathrm{CH}-\mathrm{CU}-005$. 
clay nodules - except in samples CP-PM-001 and CP-PM-004. The clay detected in several samples, including $\mathrm{CH}-\mathrm{CU}-005$, could be considered a fine aggregate although it does have bonding power.

Finally, also for the small and medium-sized lime nodules, except in samples $\mathrm{CH}-\mathrm{CU}-002, \mathrm{CH}-\mathrm{CU}-005$ and $\mathrm{CH}-\mathrm{CU}-009$ where caliches are slightly larger. Its limited porosity is observed - in this case fissured - under the microscope, as is the excellent union in the aggregate-bonding agent contacts of samples $\mathrm{CH}-\mathrm{US}-004, \mathrm{CH}-$ $\mathrm{CU}-005, \mathrm{CH}-\mathrm{CU}-007$ and $\mathrm{CH}-\mathrm{CU}-009$. Cross-referencing this data with the petrophysical analyses these samples are among the most compact of the total sample. Finally, it should be noted that this type does not contain remains of calcination or occasional vegetable remains possibly resulting from pollution, except for samples $\mathrm{CH}-$ CU-002, CH-CU-005, CH-CU-008, CH-US-005 and CH-US006. In terms of the chemical composition, it should be noted that type 2 samples have a high percentage of $\mathrm{CaO}$, above $50 \%$, and below $20 \%$ for $\mathrm{Al}_{2} \mathrm{O}_{3}$ and $\mathrm{SiO}_{2}$.

\subsection{Type 3}

The third typology corresponds to the samples with lime as bonding agent and a mineralogical phase with quartz followed by calcite with a presence of feldspar and illite. These characteristically contain high amounts of silica and lime oxide, as well as potassium oxide, sodium oxide and aluminium oxide. This third major group does not include clay minerals in its composition, as described in the following samples.

CP-PM-001: the characterization of the sample shows that this is a lime mortar in which quartz sands predominate over calcite, followed by orthoclase and albite, with the presence of illite also detected. These mineralogical phases obtained using XRD are in keeping with the XRF which show a considerable quantity of $\mathrm{CaO}$ whose origin is attributed to calcite as well as of $\mathrm{SiO}_{2}$ coming from the quartz sand, orthoclase and albite. Just as $\mathrm{NaO}_{2}$ and $\mathrm{Al}_{2} \mathrm{O}_{3}$ come from albite, illite provides $\mathrm{KO}_{2}$ and $\mathrm{Fe}_{2} \mathrm{O}_{3}$. Illite arises from thermal alteration of muscovite, and is also one of the minerals associated with clay (possibly due to onsite contamination or due to the mortar). Orthoclase and albite are feldspars, which contribute silica to the composition. As regards chemical analysis, it is worth highlighting the major PPC due mostly to the rudimentary procedure with no thermal control resulting from the production of lime in a kiln. In organoleptic terms, remains of coal or inert materials can be found (see Fig. 9).

CP-TEU-001: the sample shows the prevalence of quartz over calcite in the XRD, these are followed by orthoclase and illite. The presence of these mineralogical phases is in keeping with the XRF analysis showing large amounts of $\mathrm{SiO}_{2}$ and $\mathrm{CaO}$ (23\% and 29.8\%). The data show the use of quartz sands in the mortars, as well as carbonates. The presence of orthoclase and illite phases support the considerable presence of $\mathrm{K}_{2} \mathrm{O}, \mathrm{Al}_{2} \mathrm{O}_{3}$ and $\mathrm{Fe}_{2} \mathrm{O}_{3}$. Chemical and mineralogical characterization shows that the mortar is lime. As regards chemical analysis, it is worth highlighting the major PPC due mostly to the rudimentary procedure with no thermal control resulting from the production of lime in a kiln (see Fig. 10).

In organoleptic terms two of the main differences identified in the samples classified within type 3 , compared to those of type 2 (2a), are the size of the nodules of non-calcinated lime, as they are medium-sized, large or very large, and abundant. This is also the case of samples CP-CU-001 and CH-US-003, which do not have aggregates in the form of fired clay or clay earth in the samples, except in cases such as those of samples CP-AT-001 or CP-CU-001. Therefore, the mortars within this type correspond to a similar typology, with medium lime dosages, contrasting with the size of the lime nodules and not entirely coherent with these samples. This, combined with the absence of clay or terracotta, suggests that these mortars belong to a different construction period to those reflected in type 2 (2a). The shades of these type 3 mortars are ochre, light brown and occasionally whitish. In contrast, most of those analysed visually within type 2 (2a) are a pinkish ochre colour, perhaps due to a relative content of reddish clay or iron oxides. The chemical composition of these mortars displays a higher percentage of $\mathrm{Al}_{2} \mathrm{O}_{3}$ and $\mathrm{SiO}_{2}$, above $20 \%$, and a lower dosage of $\mathrm{CaO}$, below $50 \%$.

To conclude the visual examination of the mortars it should be noted that two samples of mortar that differed greatly from the rest were found. These were a priori classified as type 5 . As regards the mineralogical compositions no major differences were found, except that they were two of the mortars with the highest content in $\mathrm{CaO}$, between 54 and 57\%. However, during organoleptic analysis two very homogenous samples are observed, as suggested by the appearance of the constructions, which were probably made in relatively recent mortars, CP-AT-002 and CP-AT-003. When touched, both appear rather hard, although not as hard as type 2 samples $\mathrm{CH}-\mathrm{US}-004, \mathrm{CH}-\mathrm{CU}-005, \mathrm{CH}-\mathrm{CU}-007$ and $\mathrm{CH}-\mathrm{CU}-009$. They present a very regular and varied dosage of aggregate with an almost complete absence of lime nodules, without remains or alterations and in a homogenous whitish and greyish colour. In any case, as with type 4 (see the description in typology 1 ), mineralogical criteria were finally used to identify mortars of type 5 as a variant of type 2 (2c).

\subsection{Synthesis of data}

The research has employed complementary analysis, qualitative and semi-quantitative, that informs one another. That is why the authors believed that the explanation and analysis of the samples is better understood by joining the outputs of the different techniques and explaining them all together through section 4 .

The analysis of typology 1 demonstrates that some nodules of lime present in the samples was badly cooked and that is why their compactness is the lower of the series - $45 \%$. The presence of gypsum may have prevented them from being eroded; gypsum was extensively used at that time as rendering in the major cities [34]. This typology only represents the $8.4 \%$ of the total sample, representative of two specific places in the countryside. Given the findings of Cavanilles, as regards the lack of coal for calcinating the limestone, this type could belong to a very specific period, conditioned by the availability of the material and the widespread occupation of the territory, both characteristic features of the 18th century.

Typology 2 was the most complex and that is why it was finally subdivided in three sub-typos. Type 2 (2a) presented a 55-60\% of compactness, nonetheless some of the samples, as sample $\mathrm{CH}-\mathrm{CU}-$ 001 shows in the phases of the XRD, suffered from decay due to their exposition; this samples are mainly located in the country side and in the upper zones of the area of analysis. In this type 2, fundamental differences in the semi-quantitative analysis of two samples shows that CU-001 XRD pattern has much more percentage of $\mathrm{SiO}_{2}$ than $\mathrm{CU}-005$ XRD pattern which shows more $\mathrm{CaCO}_{3}$. Nonetheless the two samples have the two components in their constitution. Then, the qualitative organoleptic visualization refers to the samples' aggregates as limestone (CU-005) and sandstone (CU-001). Samples of this type did not use gypsum, nonetheless clay and fibres are present in the most of them. This type represents the $13.8 \%$ of the total sample and, the stratigraphic unit from which the samples were extracted, possibly dates them in the 14th-15th centuries.

Type 2 (2b), the most compact samples - 65\%-80\% - , used clay but not gypsum in its composition, as type 2 (2a). This samples did not present severe decay, the most of them are located in HC and represent the $27.8 \%$ of the total sample. By analyzing the type of buildings and their correlation with typology 3 , it can be stated that this type $2 \mathrm{~b}$ belongs to the 16 th and 17 th centuries. Type $2(2 \mathrm{c})$ samples may well be of poorer quality and execution $-55-60 \%$ of 


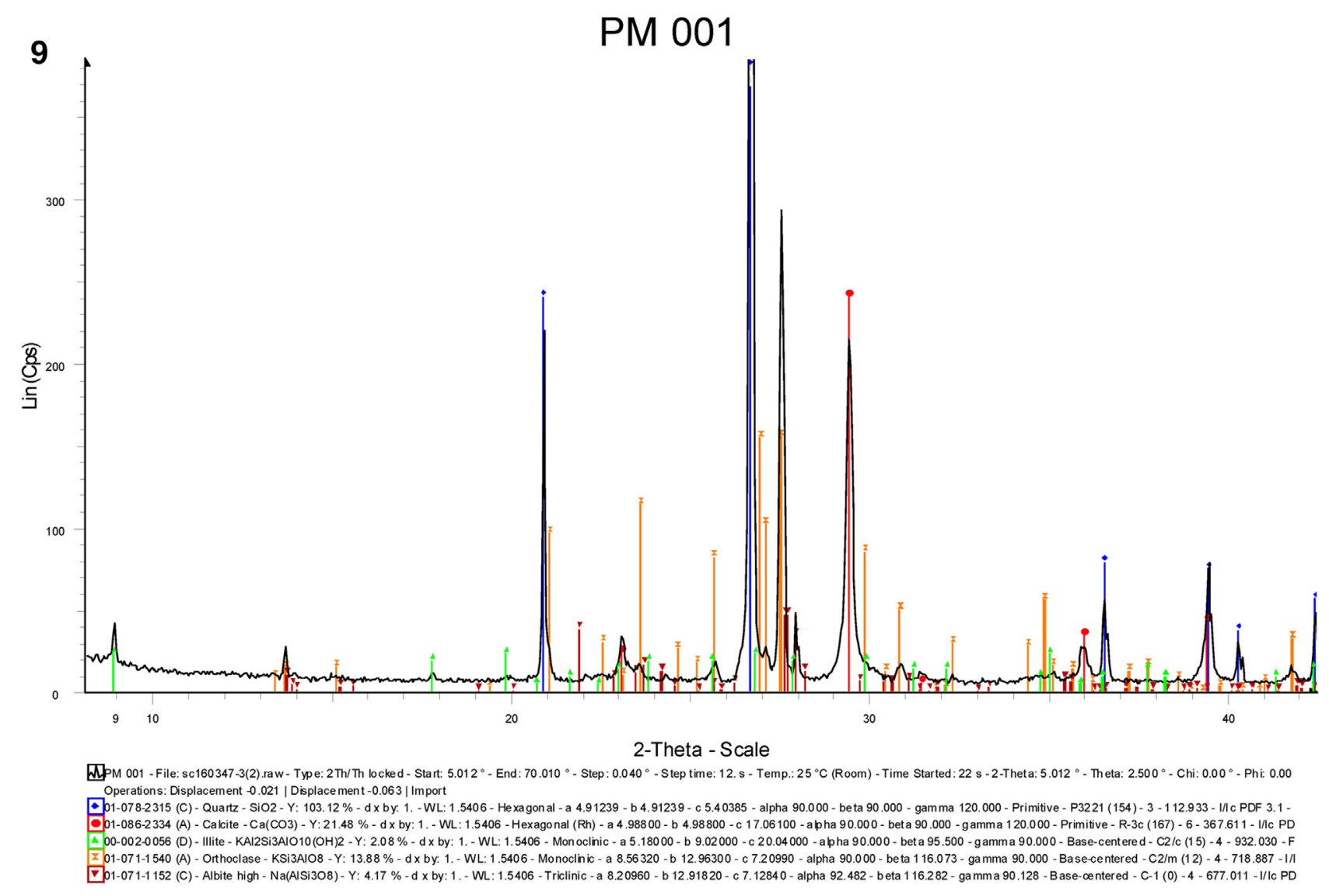

10

TEU 001

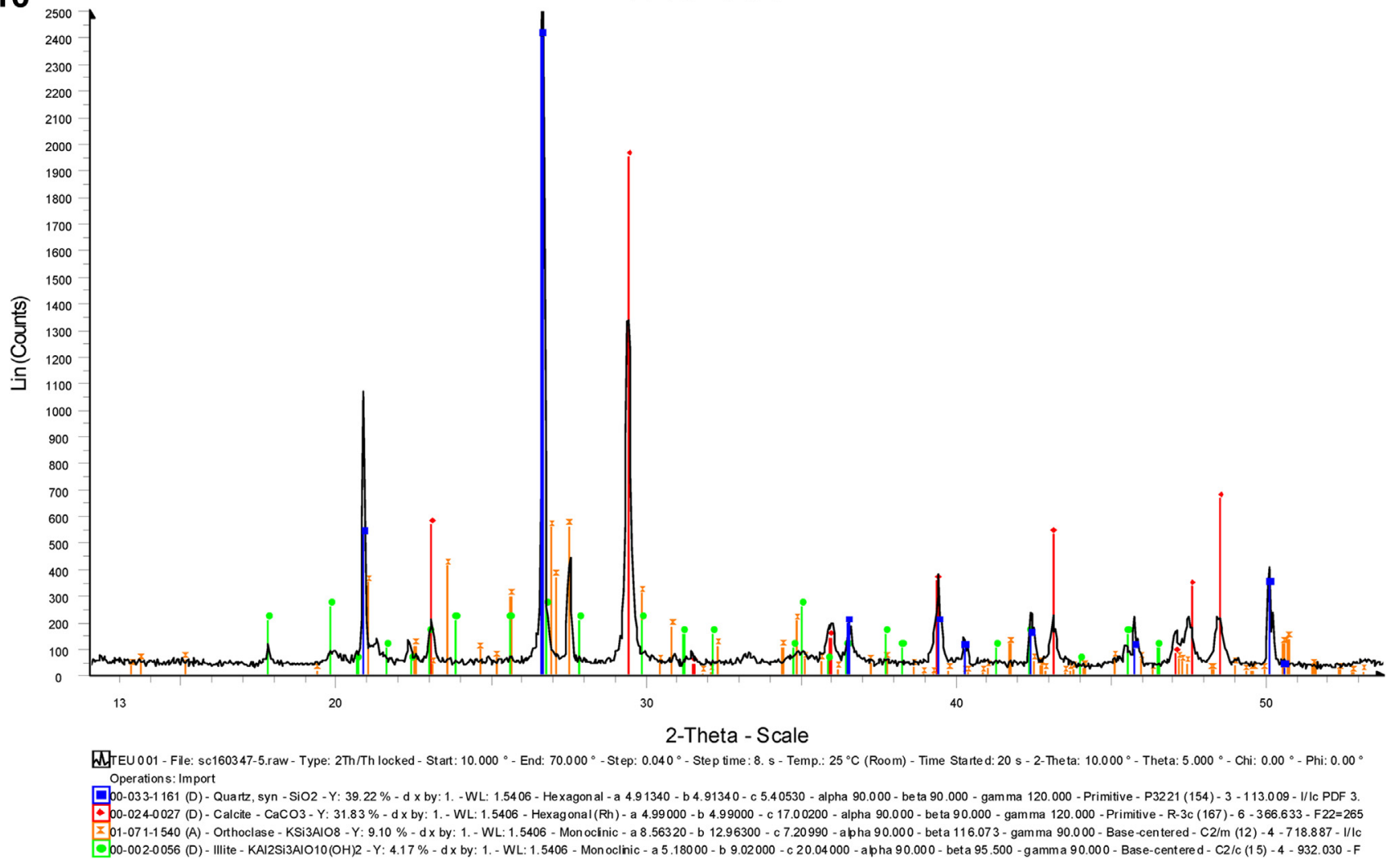

Figs. 9-10. XRD pattern of samples CP-PM-001 and CP-TEU-001. 
compactness - Samples do not present gypsum nor clay in their composition, besides they were found in both HC and PC representing just the $11.2 \%$ of the total sample. Their origin probably dates back to the 19th and 20th centuries.

In typology 3, the nomenclature of the samples establish a link between the morphology of mortars and its location, which is mainly disperse in cottages in PC and warehouses in HC located in the upper parts of the village of Culla. This type represents almost the $40 \%$ of the total sample and it is characterized by a quite good state of decay in spite of the bad quality of the mortar. Typology 3 is characterized by the absence of gypsum and clay. The limited coherence of the mortar suggests a more artisanal and less rigorous technique, as it cannot be linked solely to the rural kilns or city kilns, given that these samples are found in both settings. These conclusions, and the archive data, prompt us to conclude that they are connected with a less perfected form of constructions which was probably later than type 2 (2a) samples, between the 16 th and 17 th centuries.

\section{Conclusions}

To sum up it can be stated that the mortar used in the region since the Middle Ages it has been made of lime mortar. Given the absence of significant differences between components it is assumed that this did not depend on whether the constructions were in HC or PC. Exceptions and particularities are observed in the components of some mortars and their manufacturing process, confirmed through tests and analyses. Although we do not have an exact date for the mortars, it can be stated that there are five different mortar typologies and five differentiated construction periods that can be defined by the classes obtained with the origin of mortars; origin of material, production process, location within the building or construction period.

According to the classification and dating from this study, the initial criterion established regarding 16 th and 17 th century mortars can be assumed as valid. However, the statement that medieval mortars are poorer quality cannot be considered as valid. In our case we consider the samples to be more heterogeneous as previous authors indicated, but the dosage and are highly compact according to the chemical analysis undertaken in the study. In fact, by carefully examining the composition of the different samples, it can be stated that the main differences are found between Historic Centres $(\mathrm{CH})$ and Peripheral Constructions (CP). The dosage estimation of $\mathrm{CH}$ samples is richer in aggregate than $\mathrm{CP}$ ones. Proportions may vary from values near to $1 / 1 \mathrm{CH}$ and $1 / 2 \mathrm{CP}$ for the 14 th to 15 th centuries and 16 th to 17 th centuries. In this last period the proportion can drop eventually to $1 / 3$ in some CP samples. From the 18 th century on, mortars do not show such differences. Given the above, it can be concluded that the period of construction determines the quality of the mortar, while organoleptic analysis shows that mortar quality also depends on the process of production and/or the availability of materials and natural resources; the location.

The characterization of mortars has allowed the researchers to map and establish typologies related to a location, to a specific time in the history, and between themselves. The characterization has allowed the researchers to understand the origin, the materiality and the production process of mortars. This is of utmost importance since a Territorial Heritage Action Plan will assume some retrofit actions. These actions will imply the use of new mortars, dosages and compositions. So, what the study has demonstrated is the importance of heterogeneity in a great rural area looking for future material compatibility. Any new sample of mortar in the area can now be classified and understood inside a more global process of conservation. The importance of the study then relies on the linkages between events and epochs rather than on the materiality of buildings. So, the analysis provides more relevance to the territory, and to the relationships between buildings, ways of life and space.

\section{Funding}

This work was supported by the Regional Government of Castellón and developed by the team of the Chair of Historic Centres and Cultural Routes at Universitat Jaume I. It was also supported with funding from the project "World Heritage Cultural Landscapes List. Keys for their identification and criteria for their management" from the Ministry of Economy and Competitiveness in Spain, MINECO. CSO2015.65787-C6-6-P. Finally, the authors would also like to thank the reviewers for their invaluable comments.

\section{References}

[1] F. Gutiérrez-Solana, M. Jáuregui, R. Bohigas, P. Sarabia, Análisis de morteros medievales de dos castillos de Cantabria (España), Mater. Construcc. 39 (213) (1989) 37-45.

[2] M. Vendrell-Saz, S. Alarcón, J. Molera, M. García-Vallés, Dating ancient lime mortars by geochemical and mineralogical análisis, Archaeometry 38 (1) (1996) 143-149.

[3] A.B. Leslie, J.J. Hughes, Binder microstructure in lime mortars: implications for the interpretation of analysis results, Q.J. Eng. Geol. Hydrogeol. 35 (3) (2002) 257-263.

[4] F. Casadio, G. Chiari, S. Simon, Evaluation of binder/aggregate ratios in archaeological lime mortars with carbonate aggregate: a comparative assessment of chemical, mechanical and microscopic approaches, Archaeometry 47 (4) (2005) 67-689.

[5] S. Pavía, S. Caro, An investigation of roman mortar technology through the petrographic analysis of archaeological material, Constr. Build. Mater. 22 (2008) 1808-1811.

[6] J.I. Álvarez, A. Martín, P.J. García-Casado, I. Navarro, A. Zornoza, Methodology and validation of a hot hydrochloric acid attack for the characterization of ancient mortars, Cement Concrete Res. 29 (7) (1999) 1061-1065.

[7] O. Cazalla, M.J. de la Torre, Morteros de restauración y morteros antiguos. Técnicas de estudio, in: R. Villegas, E. Sebastián (Eds.), Metodología de diagnóstico y evaluación de tratamientos para la conservación de los edificios históricos, Instituto Andaluz del Patrimonio Histórico, Comares, Granada, 2003, pp. 36-47.

[8] A. Moropoulou, A. Bakolas, K. Bisbikou, Investigation of the technology of historic mortars, J. Cult. Herit. 1 (1) (2000) 45-48.

[9] P. Faria, F. Henriques, V. Rato, Comparative evaluation of lime mortars for architectural conservation, J. Cult. Herit. 9 (3) (2008) 338-346.

[10] J.A. García-Esparza, Are world heritage concepts of integrity and authenticity lacking in dynamism? A critical approach to Mediterranean autotopic landscapes, Landscape Res. (2017) (Editing process).

[11] J.A. García-Esparza, P. Altaba, Re-reading landscape. An approach to the historical and architectural configuration of Penyagolosa area, in: J.A. García-Esparza (Ed.), Landscape, ethnography and rituals at Penyagolosa, Universitat Jaume I, Castellón de la Plana, 2017, pp. 185-206.

[12] G. Navarro, La industria de la construcción en los países de la Corona de Aragón (ss. XIII-XVI), in: S. Cavaciocchi (Ed.), L'edilizia prima della rivoluzione industriale., Atti della XXXVI Settimana di Studi dell'Istituto Internazionali di Storia Economica, Le Monnier, Florence, 2004, pp. 167-207.

[13] C. Sambricio, La arquitectura española de la ilustración, Consejo Superior de Colegios de Arquitectos, Madrid, 1986.

[14] B. Bails, Tratado de Arquitectura Civil, 2, Colegio de Aparejadores y Arquitectos de técnicos de Murcia, Murcia, 1796, pp. 369-401.

[15] L.J. Vicat, Recherches sur le morteries", Casa Goujon, in: Librero de sus Altezas Reales, La Duquesa de Berry, Paris, 1818 ("Investigaciones experimentales sobre las cales de construcción, los hormigones y los morteros ordinarios". INTEMAC. Infoprint S.A., 1999).

[16] I. Gárate-Rojas, Artes de la cal, Munilla-Lería, Madrid, 2002, pp. 415.

[17] M.J. Cassinello, Effect of mortar joint thickness on deformability in medieval stone walls, Mater. Constr. 56 (284) (2006) 69-80.

[18] M. Fornés, Gurrea, Observaciones sobre la práctica del arte de edificar, Carrerizo, Valencia, 1841.

[19] F. Ger y Lobez, Tratado de construcción civil, La minerva extremeña, Badajoz, 1898.

[20] N. La Roca, Canteras, minas y cortes observados en los viajes de Cavanilles, Cuadernos de Geografía (1997) 425-454.

[21] F.J. Alonso, R. Bustamante, C. Díaz, J. Monjo, I. Salto, Glosario de morteros, ReCoPar 6 (2009) 33-40.

[22] AEMET.,AEMET Climatic data in Spain 2015.(accessed on: 16th October 2015; available at: http://www.aemet.es).

[23] J.M. García-de Miguel, Procesos de degradación de la piedra, in: L. Mas-Guindal (Ed.), Procedimientos y técnicas constructivas del Patrimonio, Munilla-Lería, Madrid, 1999, pp. 175-183.

[24] B. Agulleiro, J.J. Alonso, Estudio del residuo insoluble de rocas carbonatadas españolas, Bol. Real Soc. Esp. 70 (1972) 29-54 [Historia Natural (Sec. Geológica)]. 
[25] RILEM, Recommended tests to measure the deterioration of stone and to assess the effectiveness of treatement methods, in: Commission 25-PEM : protection et erosion des monuments, 1980, pp. 175-253.

[26] ISMR, Suggested methods for laboratory testing of argillaceous swelling rocks, Int. J. Rock Mech. Mining Sci. 26 (5) (1981) 415-427.

[27] ASTM, Construction, in: Annual Book of ASTM Standards, ASTM, Pennsylvania, 1988, pp. 8

[28] NORMAL, Assorbimen to d'aqua per immersion totale, in: Capacità di imbibizione, 1981, pp. 7-81.

[29] UNE, Catálogo de normas UNE 1993, Instituto Español de Normalización, Centro Superior de Investigaciones Científicas, Madrid, 1985.

[30] M.J. de la Torre, Estudio de los materiales de construcción de la Alhambra, Universidad de Granada, Granada, 1995.
[31] R.M. Mellinger, Quantitative X-ray diffraction analysis of clay minerals, in: An evaluation, Saskatchewan Research Council G-79, Saskatchewan, 1979, pp. $1-46$.

[32] M.J. de la Torre, J. Rodríguez, E. Sebastian, Presencia de yeso en morteros y hormigones nazaríes en la Alhambra, Bull. Soc. Esp. Mineral. 14 (1) (1991) 3-4.

[33] T. Kawiak, Gypsum mortars from a twelfth-century church in Wíslica, Poland, Stud. Conserv. 36 (3) (1991) 142-180.

[34] V. La Spina, C. Mileto, F. Vegas, The historical renderings of Valencia (Spain): an experimental study, J. Cult. Herit. 145 (2013) 544-551.

[35] J.M. García-Ruíz, J.L. Amorós, Sobre la precipitación polimórfica del carbonato cálcico, Stud. Geol. 36 (1980) 193-200. 